\title{
ARTICLE
}

\section{Strengthening the Paris Agreement by Holding Non-State Actors Accountable: Establishing Normative Links between Transnational Partnerships and Treaty Implementation}

\section{Charlotte Streck*}

First published online 18 May 2021

\begin{abstract}
While the intergovernmental climate regime increasingly recognizes the role of non-state actors in achieving the goals of the Paris Agreement (PA), the normative linkages between the intergovernmental climate regime and the non-state dominated 'transnational partnership governance' remain vague and tentative. A formalized engagement of the intergovernmental climate regime with transnational partnerships can increase the effectiveness of partnerships in delivering on climate mitigation and adaptation, thereby complementing rather than replacing government action. The proposed active engagement with partnerships would include (i) collecting and analyzing information to develop and prioritize areas for transnational and partnership engagement; (ii) defining minimum criteria and procedural requirements to be listed on an enhanced Non-state Actor Zone for Climate Action platform; (iii) actively supporting strategic initiatives; (iv) facilitating market or non-market finance as part of Article 6 PA; and (v) evaluating the effectiveness of partnerships in the context of the enhanced transparency framework (Article $13 \mathrm{PA}$ ) and the global stocktake (Article 14 PA). The UNFCCC Secretariat could facilitate engagement and problem solving by actively orchestrating transnational partnerships. Constructing effective implementation partnerships, recording their mitigation and adaptation goals, and holding them accountable may help to move climate talks from rhetoric to action.
\end{abstract}

Keywords: Transnational partnerships, Non-state actors, Paris Agreement, Climate governance, Transnational governance

* Climate Focus, Berlin (Germany) and University of Potsdam (Germany).

Email: C.Streck@climatefocus.com.

The author wishes to express her highest appreciation for the three anonymous reviewers who are responsible for significant improvements and have greatly contributed to the article in its final form. I am grateful for their time and patience. 


\section{A CASE FOR STRATEGIC ENGAGEMENT WITH TRANSNATIONAL REALITIES}

Despite all efforts, the last three decades of multilateral engagement to address climate change have lacked ambition and conviction. In December 2019, state parties to the United Nations Framework Convention on Climate Change (UNFCCC) ${ }^{1}$ merely reiterated in the 'Chile Madrid Time for Action' - the main negotiated outcome of the $25^{\text {th }}$ session of the Conference of the Parties $(\mathrm{COP})^{2}-$ 'the urgent need to address the significant gap between the aggregate effect of Parties' mitigation efforts in terms of global annual emissions of greenhouse gases by 2020 and aggregate emission pathways consistent with holding the increase in the global average temperature to well below $2{ }^{\circ} \mathrm{C}^{3}{ }^{3}$ the temperature goal of the Paris Agreement $(\mathrm{PA}) .{ }^{4}$ Despite these efforts to summon governments into action, it is obvious that national governments suffer from a painful dearth of creativity on how to re-imagine a society that is independent of fossil fuel and resource abuse.

Non-state actors (NSAs) have been eager to fill the space opened by the inadequacies of existing intergovernmental cooperation with partnerships, networks, and other more or less formal initiatives to design solutions for public policy problems. An increase in cooperation and coordination of policy agendas between NSAs and public agencies across different levels of government outside formalized diplomatic channels has led to institutional innovation ${ }^{5}$ and new forms of governance. ${ }^{6}$ Transnational cooperation has become a common feature of problems that cannot be solved by single actors, including governments. This is particularly palpable in climate change

1 New York, NY (US), 9 May 1992, in force 21 Mar. 1994, available at: https://unfccc.int/resource/docs/ convkp/conveng.pdf.

2 The decision was adopted in three formats, by the COP as well as by the governing bodies of the Kyoto Protocol (CMP) and the Paris Agreement (CMA).

3 UNFCCC, Decision 1/CMA.2, 'Chile Madrid Time for Action' (2 Dec. 2019), UN Doc. FCCC/PA/CMA/ 2019/6/Add.1, para. 8; a repetition of the preambular text in UNFCCC, Decision 1/CP.21, 'Adoption of the Paris Agreement' (13 Dec. 2015), UN Doc. FCCC/CP/2015/10/Add.1.

4 Paris (France), 12 Dec. 2015, in force 4 Nov. 2016, available at: http://unfccc.int/paris_agreement/items/ 9485.php (Paris Agreement), Art. 2.1(b).

5 P. van Ham, 'Transnational Governance and Democratic Legitimacy: A Conceptual Overview', in P. van Ham et al. (eds), Special Report on Transnational Governance and Democratic Legitimacy (The Hague Institute of Global Justice \& Netherlands Institute of International Relations (Clingendael), 2014), pp. 5-22, at 8 .

6 M. Di Gregorio et al., 'Multi-Level Governance and Power in Climate Change Policy Networks' (2019) 54 Global Environmental Change, pp. 64-77; M. Paterson, 'Networks and Coordination in Global Climate Governance', in R.N. Stavins \& R.C. Stowe (eds), The Paris Agreement and Beyond: International Climate Change Policy Post-2020 (Harvard Project on Climate Agreements, 2016), pp. 83-86; P. Pattberg \& O. Widerberg, 'Transnational Multistakeholder Partnerships for Sustainable Development: Conditions for Success' (2016) 45(1) Ambio, pp. 42-51; K.W. Abbott, 'Strengthening the Transnational Regime Complex for Climate Change' (2014) 3(1) Transnational Environmental Law, pp. 57-88; L.B. Andonova, M.M. Betsill \& H. Bulkeley, 'Transnational Climate Governance' (2009) 9(2) Global Environmental Politics, pp. 52-73; P. Pattberg et al., Public-Private Partnerships for Sustainable Development (Edward Elgar, 2012); K. Bäckstrand, 'Multi-Stakeholder Partnerships for Sustainable Development: Rethinking Legitimacy, Accountability and Effectiveness' (2006) 16(5) European Environment, pp. 290-306; K. Bäckstrand, 'Accountability of Networked Climate Governance: The Rise of Transnational Climate Partnerships' (2008) 8(3) Global Environmental Politics, pp. $74-102$. 
governance where a surge of transnational partnerships seeks to address various aspects of climate policy, ranging from information collecting and sharing, to capacity building and implementation, to rule and standard setting. ${ }^{7}$

Confronted with an explosion of transnational governance arrangements, UNFCCC engagement with these initiatives remains opportunistic. In November 2020, the UNFCCC Climate Action Portal recorded 27,175 climate commitments by 10,690 cities, 243 regions, 3,973 companies, 1,133 investors, 1,890 civil society organizations that contribute to the implementation of the PA, and 149 transnational partnerships that align with the commitments, norms and principles of intergovernmental climate action. $^{8}$ So far, however, there does not seem to be an overarching strategy underpinning the various efforts of the UNFCCC Secretariat or the various COP chairs that would go beyond a pragmatic effort to harness private energy, implementation capacity, and capital. Despite efforts to orchestrate private action through a variety of 'Climate Action'" work streams and programmes, there is little direct normative or institutional engagement between the formal, intergovernmental and the informal, transnational climate sphere.

It remains unclear what NSAs are expected to contribute to the achievement of the objectives of the PA, how they are encouraged to do so, whether and how they should be held accountable and, maybe most importantly, how their efforts can complement and strengthen government actions. Consequently, it is worth considering how transnational climate governance can be strengthened through formal links between NSA partnerships and the compliance framework of the PA. This involves consideration of how orchestration can be linked to formal aspects of the PA, such as the cooperative mechanisms contemplated under Article 6 and the transparency framework established under Article 13. Normative considerations such as enhanced effectiveness need to be calibrated with democratic values such as accountability, participation, and transparency.

In recent years, scholars have developed a number of proposals on how to improve climate governance in which NSAs play an increasingly prominent role. ${ }^{10}$ As has been

7 Andonova, Betsill \& Bulkeley, n. 6 above, p. 66.

8 Global Climate Action, available at: https://climateaction.unfccc.int.

9 The 'Climate Action' tab on the UNFCCC website refers to action that must come from governments, cities, regions, businesses and investors, available at: https:/unfccc.int/climate-action/introduction-climate-action.

10 E.g., K.W. Abbott \& D. Snidal, 'Strengthening International Regulation through Transnational New Governance: Overcoming the Orchestration Deficit' (2009) 42(2) Vanderbilt Journal of Transnational Law, pp. 501-78; K.W. Abbott, 'The Transnational Regime Complex for Climate Change' (2012) 30(4) Environment and Planning C: Government and Policy, pp. 571-90. S. Chan \& W.P. Pauw, 'A Global Framework for Climate Action: Orchestrating Non-State and Subnational Initiatives for More Effective Global Climate Governance', Deutsches Institut für Entwicklungspolitik, Report No. 34/2014, Jan. 2014; K.W. Abbott \& T. Hale, 'Orchestrating Global Solutions Networks: A Guide for Organizational Entrepreneurs' (2014) 9(1-2) Innovations: Technology, Governance, Globalization, pp. 195-212; T. Hale \& C. Roger, 'Orchestration and Transnational Climate Governance' (2014) 9(1) The Review of International Organizations, pp. 59-82; K. Bäckstrand \& J.W. Kuyper, 'The Democratic Legitimacy of Orchestration: The UNFCCC, Non-State Actors, and Transnational Climate Governance' (2017) 26(4) Environmental Politics, pp. 764-88; S. Chan \& W. Amling, 'Does Orchestration in the Global Climate Action Agenda Effectively Prioritize and Mobilize Transnational Climate Adaptation Action?' (2019) 19(4) International Environmental Agreements: Politics, Law and Economics, 
proposed in the context of 'experimentalist governance', it is much easier to forge consensus among a smaller group of actors on how to solve component problem areas than to devise broad solutions for a global problem. ${ }^{11}$ Elinor Ostrom's polycentric governance model draws its strength from recognizing that complex problems require action at all levels of governance, ${ }^{12}$ in particular with regard to the involvement of 'lower-level' or contextually situated actors who have knowledge of local conditions and are best placed to implement action that leads to the achievement of defined goals. ${ }^{13}$ The knowledge and experience of regional or sectoral success stories can then lead to replication and scaling up of successful strategies. However, there is also a growing understanding that transnational governance is unlikely to reach its potential in the absence of public authority. $^{14}$

In this article I make the case for a more explicit policy towards NSA and partnership engagement in the context of the UNFCCC and the PA. Formal spaces of interaction and orchestration embedded in clear rules of engagement could significantly increase the effectiveness of the climate regime. I will present a number of proposals for such engagement. In doing so, I am keenly aware that a formalization of engagement would not come without risk. Most notably, transnational initiatives must be integrated into the normative fabric of the UNFCCC-centred climate regime without clipping their wings. Further, NSA action should complement government action, not replace it. Done right, proactive engagement with NSAs within a normative context can provide an energy boost to the 'ossified' 15 climate regime and enhance its effectiveness. If done poorly, it can further dilute the credibility of the regime and institutionalize the opportunity for 'greenwash' by private actors.

This article is structured as follows. The next section briefly summarizes the evolution of NSA engagement under the climate regime. Section 3 discusses the current

pp. 429-46; K.W. Abbott, 'Orchestration: Strategic Ordering in Polycentric Climate Governance', SSRN Electronic Journal, 8 June 2017, available at: http://www.ssrn.com/abstract=2983512.

11 C.F. Sabel, 'Governing Global Problems under Uncertainty: Making Bottom-Up Climate Policy Work' (2017) 144(1) Climatic Change, pp. 15-27, at 18. See also G. de Búrca, R.O. Keohane \& C.F. Sabel, 'Global Experimentalist Governance' (2014) 44(3) British Journal of Political Science, pp. 477-86; C.F. Sabel \& D.G. Victor, 'Governing Global Problems under Uncertainty: Making Bottom-Up Climate Policy Work' (2017) 144 Climatic Change, pp. 15-27.

12 E. Ostrom, 'A Multi-Scale Approach to Coping with Climate Change and Other Collective Action Problems' (2010) 1(2) Solutions, pp. 27-36; E. Ostrom, 'A Polycentric Approach for Coping with Climate Change', Policy Research Working Paper 5095, Oct. 2009, The World Bank.

13 De Búrca, Keohane \& Sabel, n. 11 above, p. 478.

14 S. Chan, C. Brandi \& S. Bauer, 'Aligning Transnational Climate Action with International Climate Governance: The Road from Paris' (2016) 25(2) Review of European, Comparative \& International Environmental Law, pp. 238-47; K. Michaelowa \& A. Michaelowa, 'Transnational Climate Governance Initiatives: Designed for Effective Climate Change Mitigation?' (2017) 43(1) International Interactions, pp. 129-55; Bäckstrand \& Kuyper, n. 10 above; L.B. Andonova, T.N. Hale \& C.B. Roger, The Comparative Politics of Transnational Climate Governance (Routledge, 2019); Chan \& Amling, n. 10 above; Å. Persson \& A. Dzebo, 'Special Issue: Exploring Global and Transnational Governance of Climate Change Adaptation' (2019) 19(4) International Environmental Agreements: Politics, Law and Economics, pp. 357-67.

15 J. Depledge, 'The Opposite of Learning: Ossification in the Climate Change Regime' (2006) 6(1) Global Environmental Politics, pp. 1-22, at 2 (describing an ossifying regime as one that, even if it receives new technical or scientific input, fails to process that input in any meaningful way). 
challenge of legitimacy for NSA-led partnerships in the context of the PA. Based on that analysis, a framework for the normative interaction between private and public forms of climate governance is presented. This leads to a proposal in Section 4 on how NSA action and transnational partnerships can be embedded more formally in the international climate regime. To further concretize the proposed framework for engagement, Section 5 discusses how Article $6 \mathrm{PA}$ can provide an umbrella for transnational partnerships. After a short discussion on risks in Section 6, the article concludes by summarizing how the proposed reforms can strengthen the effectiveness and resilience of the PA.

\section{THE ADVENT OF TRANSNATIONAL PARTNERSHIPS UNDER THE UNFCCC}

NSAs have participated in addressing climate change from the moment it was recognized as a global problem. In addition to permitting NSAs to attend UNFCCC sessions as observers (Article 7(6)) the Convention addresses the role of non-governmental entities in the context of training and awareness raising (Article 4(1)(i)) and as resources and providers of information (Article 7(2)(1)). The Kyoto Protocol ${ }^{16}$ reiterates the right of non-governmental organizations (NGOs) to participate in meetings of state parties (Article 13(8)) and mandates parties to seek non-governmental support to promote the effective implementation of the Protocol (Article 13(4)(i)). In addition, the Protocol assigns an explicit role to public and private entities in authorizing their participation in the Clean Development Mechanism (CDM) (Article 12(9)) and Joint Implementation (Article 6(3)) projects, and emphasizes their role in the transfer of environmentally sound technologies (Article 10(c)). The inclusion of NSAs in carbon markets and technology transfer recognizes that private corporations and financial organizations must drive much of the eventual innovation and implementation of climate measures. ${ }^{17}$

The PA formulates a mechanism of international cooperation which carries over features of the CDM into the new accord. The PA, in Article 6(4), defines a mechanism which aims to 'incentivize and facilitate participation in the mitigation of greenhouse gas emissions by public and private entities authorized by a Party'. However, it goes beyond providing state parties with the option to authorize NSA participation in carbon market mechanisms when it acknowledges in its Preamble 'the importance of the engagements of all levels of government and various actors' in achieving the goals of the PA. The role of public and private sector participation in the implementation of 'nationally determined contributions' (NDCs) of state parties is further emphasized in Article 6(8)(b).

16 Kyoto (Japan), 11 Dec. 1997, in force 16 Feb. 2005, available at: http://unfccc.int/kyoto_protocol/items/ 2830.php.

17 C. Streck, 'Filling in for Governments? The Role of the Private Actors in the International Climate Regime' (2020) 17(1) Journal for European Environmental \& Planning Law, pp. 5-28, at 13. 
The state parties adopting the PA also explicitly agreed 'to uphold and promote regional and international cooperation in order to mobilize stronger and more ambitious climate action by all Parties and non-Party stakeholders, including civil society, the private sector, financial institutions, cities and other subnational authorities, local communities and indigenous peoples'. ${ }^{18}$ Parties also welcome 'the efforts of all non-Party stakeholders to address and respond to climate change, including those of civil society, the private sector, financial institutions, cities and other subnational authorities', ${ }^{19}$ and encourage 'them to register those actions in the Non-state Actor Zone for Climate Action platform'. ${ }^{20}$

The active courting of NSAs by the UNFCCC Secretariat and multilateral organizations, combined with an increased interest in using the stage provided by international climate conferences, has led to a surge in side events, announcements, and gatherings convened around particular issues and implementation challenges. Today, the 2016 Marrakech Partnership for Global Climate Action (MPGCA) ${ }^{21}$ serves as an umbrella for various private initiatives. Before the launch of the MPGCA, the Lima-Paris Action Agenda (LPAA) ${ }^{22}$ brought 'both state and non-state actors together on the global stage to accelerate cooperative climate action now and into the future in support of the new agreement'. ${ }^{23}$ The MPGCA is spearheaded by high-level climate champions and includes the Non-state Actor Zone for Climate Action (NAZCA) and the Climate Action Portal, the publication of the Yearbook of Climate Action and Climate Action Pathways, as well as the organization of regional climate weeks and climate action summits. ${ }^{24}$ In 2019, COP-25 appointed new high-level climate champions to serve until 2025 and mandated them to improve the work under the MPGCA with a view to enhancing ambition. ${ }^{25}$

There is also engagement of NSAs in various UNFCCC workstreams, such as adaptation and technology transfer. The UNFCCC Nairobi Work Programme Private Sector Initiative offers networking opportunities, access to knowledge, as well as reputational advantages and increased visibility. ${ }^{26}$ The consideration of private capabilities and interests has also played an important role in designing frameworks for the development, deployment, and transfer of technologies. The Climate Technology Centre and Network, ${ }^{27}$ established as part of the 2010 Technology Mechanism, coordinates a worldwide network of organizations that provide local private and public actors

18 Decision 1/CP.21, n. 3 above, Preamble

19 Ibid., para. 134

20 Ibid., paras 118 and 135

21 Available at: https://unfccc.int/climate-action/marrakech-partnership-for-global-climate-action.

22 Available at: https://cop23.unfccc.int/news/welcome-to-the-lpaa-website-learn-more-about-the-transformationalinitiative.

23 Ibid.

24 N. 21 above.

25 UNFCCC, Decision 1/CP.25, 'Chile Madrid Time for Action' (2 Dec. 2019), UN Doc. FCCC/CP/2019/ 13/Add.1, paras 23, 24.

26 UNFCCC Secretariat, 'Adaptation Private Sector Initiative (PSI)', available at: https://unfccc.int/topics/ resilience/resources/adaptation-private-sector.

27 'About the Climate Technology Centre and Network', available at: https://ctc-n.org/about-ctcn. 
with information to facilitate coordination on technology solutions. ${ }^{28}$ In negotiations for effective technology development, transfer and deployment, private sector involvement became a necessity earlier than was the case for other UNFCCC agenda items. However, the rest of the system has caught up. The empowerment of private action through the PA is a clear response to the power and influence that private and non-state public actors wield internationally.

By abandoning a system of top-down negotiated greenhouse gas (GHG) mitigation targets, the PA acknowledges the primacy of domestic climate politics ${ }^{29}$ and relies on countries to define their capacity and communicate their planned efforts to contribute to climate change mitigation and adaptation. In the ten years between the start of the 'post-Kyoto' negotiations in 2005 and the adoption of the PA, the international community has proved unable to devise and agree on a fair and effective way to formalize a sharing of the mitigation burden. The transition from the top-down system of the Kyoto Protocol to the bottom-up logic of the PA is also a diplomatic response to a world that is increasingly shaped by a multitude of actors and initiatives. It is widely recognized that an agreement between states alone cannot protect global public goods and that domestic, local, and transnational efforts and initiatives are essential in the formulation of climate policies.

Transnational partnerships include public and private (multi-sectoral) actors and seek to achieve public policy goals through a networked, non-hierarchical governance structure $^{30}$ and pursue their collaboration in at least two states. ${ }^{31}$ Subnational jurisdictions, NGOs and, to a lesser extent, corporations drive initiatives that seek to coordinate action across public and private stakeholders, often bringing together actors with an interest in a particular economic sector or geography. Examples of transnational partnerships include the Tropical Forest Alliance, a 'multi-stakeholder partnership platform, initiated to support the implementation of private-sector commitments to remove deforestation from palm oil, beef, soy, and pulp and paper from their supply chains', 32 the Net Zero Carbon Buildings Commitment which 'challenges companies, cities, states and regions to reach Net Zero operating emissions in their portfolios by 2030, and to advocate for all buildings to be Net Zero in operation by 2050 , 33 or the Climate and Clean Air Coalition, 'a voluntary partnership of governments, intergovernmental organizations, businesses, scientific institutions and civil society organizations committed to improving air quality and protecting the climate through actions to reduce short-lived climate pollutants'. ${ }^{34}$ In addition to

28 M. Glachant \& A. Dechezleprêtre, 'What Role for Climate Negotiations on Technology Transfer?' (2017) 17(8) Climate Policy, pp. 962-81, at 972.

29 R. Falkner, 'The Paris Agreement and the New Logic of International Climate Politics' (2016) 92(5) International Affairs, pp. 1107-25, at 1107.

30 Pattberg \& Widerberg, n. 6 above, p. 43.

31 C. Roger \& P. Dauvergne, 'The Rise of Transnational Governance as a Field of Study' (2016) 18(3) International Studies Review, pp. 415-37, at 416.

32 Available at: https://www.tropicalforestalliance.org.

33 World Green Building Council, available at: https://www.worldgbc.org.

34 Available at: https://www.ccacoalition.org. 
these multi-sectoral initiatives, there are countless industry initiatives (such as Improve Water Security - Business Alliance for Water and Climate ${ }^{35}$ or Fashion Industry for Climate Action ${ }^{36}$ ), some with the participation of NGOs (such as Climate Action $100+{ }^{37}$ ), or networks of cities and regions (such as the Carbon Neutral Cities Alliance $^{38}$ or the Covenant of Mayors for Climate \& Energy ${ }^{39}$ ).

The results are partnerships that define modes of implementation and set standards that guide their cooperation. In many partnership settings NSAs have evolved from rule takers to rule makers. ${ }^{40}$ The result is 'polycentric' forms of governance involving multiple centres of semi-autonomous decision making. ${ }^{41}$ These forms of governance overlap and interact with intergovernmental governance, but are conceptually different. The question is how and to what extent intergovernmental governance, as embodied by the UNFCCC-based climate regime, can positively define such interaction and thereby increase the chances of meeting the temperature goals of the PA.

\section{LEGITIMACY CHALLENGES IN CURRENT NSA INVOLVEMENT}

Over time, UNFCCC parties have opened a number of avenues of NSA engagement - at first timidly and, since the adoption of the PA, with increased determination. These efforts have grown in parallel with an 'organic' surge of NSA-driven climate action. The result is hybrid governance ${ }^{42}$ where transnational partnerships operate alongside formal climate negotiations, setting goals, formulating rules of engagement, creating standards, and making funding decisions across various sectors and governance levels.

Catalyzing the energy and the ability to innovate and implement, and activating the financial muscle of private and subnational public actors, are indispensable actions for meeting the temperature target of the PA. With its implementation and innovation capacity, global connections and command over financial resources, the private sector is essential for building the infrastructure and deploying the technologies of low emitting economies. However, there is also emerging agreement that NSAs have a direct responsibility to contribute to climate change mitigation. It is not sufficient to regulate highemitting industries in their home country if they generate most of their harm in their supply chains, or if polluting operations are far from decision-making headquarters.

35 Available at: https://ceowatermandate.org.

36 E.g., the Fashion Industry Charter for Climate Action, available at: https:/unfccc.int/climate-action/sectoralengagement/global-climate-action-in-fashion/about-the-fashion-industry-charter-for-climate-action.

37 Climate Action $100+$ is an initiative by investors to engage systemically important GHG emitters, available at: https://www.climateaction100.org.

38 Available at: https://carbonneutralcities.org/cities.

39 Available at: https://www.covenantofmayors.eu.

40 J.C.S. Andrade \& J.A. Puppim de Oliveira, 'The Role of the Private Sector in Global Climate and Energy Governance' (2015) 130(2) Journal of Business Ethics, pp. 375-87, at 378.

41 Ostrom, n. 12 above; J. Mansbridge, 'The Role of the State in Governing the Commons' (2014) 36 Environmental Science \& Policy, pp. 8-10; K. Carlisle \& R.L. Gruby, 'Polycentric Systems of Governance: A Theoretical Model for the Commons' (2019) 47(4) Policy Studies Journal, pp. 927-52; Abbott \& Hale, n. 10 above.

42 K. Bäckstrand et al., 'Non-State Actors in Global Climate Governance: From Copenhagen to Paris and Beyond' (2017) 26(4) Environmental Politics, pp. 561-79, at 562. 
It has been argued that emitting GHGs violates the no-harm principle of international law, ${ }^{43}$ and courts have started to apply a similar logic to non-state polluters. ${ }^{44}$ This may imply that the decision of any major - public or private - emitter to contribute its 'fair' share towards resolving the climate crisis is no longer fully voluntary. Opening the intergovernmental climate regime towards a more formal interaction with transnational NSA initiatives reflects such an evolving understanding of effective climate policymaking.

However, NSA engagement in the context of the climate regime also entails risks. Transnational partnerships are plagued by concerns over a lack of legitimacy and, with expressions of 'liberal environmentalism' or 'green neoliberalism', have been accused of eroding state governance. ${ }^{45}$ Where forms of governance dominated by nonstate interests lead to a scaling back of mandatory regulation and a privatization of environmental resources, the resulting regime may well be biased towards private concerns and fail to consider the needs of developing countries and vulnerable populations. $^{46}$

Building legitimacy remains a challenge for transnational partnerships. They lack a democratic mandate as a normative source of legitimacy; most partnerships are informal in nature and voluntary in participation. In the absence of democratic legitimacy, legitimacy can be conferred by public acceptance and the general agreement that certain activities or players credibly and effectively contribute to the public good. Such perceived legitimacy is generally associated with enhanced democratic values such as transparency, participation, and accountability. ${ }^{47}$ Just as NSA partnerships span a wide range of different organizational forms, their fulfilment of said democratic values remains inconsistent, as illustrated in the following areas:

- Accountability Depending on the nature of transnational partnerships, individual partners may 'internally' be accountable to their particular constituencies: cities to their citizens, companies to their shareholders, NGOs to their members and donors. Externally, the linking of NSA-led partnerships through the MPGCA and NAZCA to the PA shows an emerging internal relationship of accountability between such initiatives and the intergovernmental climate regime. ${ }^{48}$ However, there is currently insufficient screening and monitoring of NSA initiatives and a

43 B. Mayer, 'Construing International Climate Change Law as a Compliance Regime' (2018) 7(1) Transnational Environmental Law, pp. 115-37.

44 A comprehensive listing of climate cases, including those filed against corporates, is available at: http://climatecasechart.com.

45 K. Bakker, "The "Commons" versus the "Commodity": Alter-globalization, Anti-privatization and the Human Right to Water in the Global South' (2007) 39(3) Antipode, pp. 430-55, at 431.

46 D. Ciplet \& J.T. Roberts, 'Climate Change and the Transition to Neoliberal Environmental Governance' (2017) 46 Global Environmental Change, pp. 148-56, at 150, 153.

47 Bäckstrand \& Kuyper, n. 10 above, pp. 770-4. See also K. Bäckstrand, F. Zelli \& P. Schleifer, 'Legitimacy and Accountability in Polycentric Climate Governance', in A. Jordan et al. (eds), Governing Climate Change (Cambridge University Press, 2018), pp. 338-56.

48 For a discussion of the various forms of accountability, see O. Widerberg \& P. Pattberg, 'Accountability Challenges in the Transnational Regime Complex for Climate Change' (2017) 34(1) Review of Policy Research, pp. 68-87. 
lack of criteria for their inclusion in these climate action platforms. This oversight is problematic, in particular where NSA action is framed as complementary to or even compensatory for state action. ${ }^{49}$ While the association with the UNFCCC confers legitimacy on partnerships, currently no process or regulating entity would hold them accountable for their goals and vis-à-vis their constituencies, and few partnerships have mechanisms for internal or external accountability. ${ }^{50}$

- Transparency Transparency and due process requirements could enable accountability, as they provide NGOs, the media and individuals with the information they need to check and monitor transnational climate action. So far, however, partnerships have applied limited rules in relation to the measurement, reporting and verification (MRV) of their implementation and impact. NSAs can register their initiatives with NAZCA, which overall is little more than an inventory of international climate initiatives. NAZCA does not monitor emissions reductions and fails to hold partnerships accountable for their pledges. Further, these pledges lack any formal link to the implementation of the PA. The 'enhanced transparency framework' of the PA includes references to NSAs as 'technical experts' (Article 13.11), but does not contemplate a review of transnational partnership and NSA climate action.

- Participation The overwhelming number of partnerships are led by developed country partners. ${ }^{51}$ Consequently, developing country partners do not have equal influence in defining partnerships' objectives or governance. As most partnerships concern themselves with global networking coordination, the involvement of local stakeholders remains very low. ${ }^{52} \mathrm{~A}$ bias towards the interests of the most powerful actors limits the acceptance of transnational partnerships, in particular if they carry the risk of providing an excuse for a retreat of public authority and concern. While representatives of private enterprises tend to see themselves as agents of solutions and action, that self-perception is not always matched by the views of state parties and other NSAs. ${ }^{53}$ So far, the modus of participation in transnational climate partnerships remains opportunistic and few partnerships are embedded in broader decarbonization strategies.

These shortcomings may prove inconsequential if partnerships succeed in overcoming the implementation challenges that afflict the 'wicked social problem's4 of climate

49 Bäckstrand \& Kuyper, n. 10 above, p. 782.

50 For a definition and description of the elements of accountability see R.W. Grant \& R.O. Keohane, 'Accountability and Abuses of Power in World Politics' (2005) 99(1) American Political Science Review, pp. 29-43, at 29.

51 S. Chan et al., 'Effective and Geographically Balanced? An Output-based Assessment of Non-State Climate Actions' (2018) 18(1) Climate Policy, pp. 24-35.

52 Katharina Michaelowa and Axel Michaelowa found in an analysis of 109 transnational initiatives that the main purpose of most initiatives is networking: Michaelowa \& Michaelowa, n. 14 above, p. 151.

53 N. Nasiritousi, M. Hjerpe \& B.-O. Linnér, 'The Roles of Non-State Actors in Climate Change Governance: Understanding Agency through Governance Profiles' (2016) 16(1) International Environmental Agreements: Politics, Law and Economics, pp. 109-26, at 120.

54 R. Grundmann, 'Climate Change as a Wicked Social Problem' (2016) 9(8) Nature Geoscience, pp. 562-3. 
change. The flexibility of issue-specific partnerships and the multitude of actors that define agendas, adopt rules, agree on standards and codes of conduct can make climate policy more resilient in the light of the shortcomings of state-led governance and slow policy processes. ${ }^{55}$ Partnerships may increase trust and create platforms for interaction and cooperation, ${ }^{56}$ and the standards that they set are often more ambitious than government-sponsored rules. ${ }^{57}$ As complex problems require complex and multi-scale solutions ${ }^{58}$ it seems prudent to encourage efforts at all governance levels, ensuring that solutions are responding to local circumstances.

However, the fact that NSAs have certain benefits over states - they are quicker, more adaptive and flexible, nimbler and more innovative in the definition of solutions, and endowed with unique resources and capacities - cannot be allowed to lead to a renunciation of public responsibility and an abdication of government powers, especially while the actual effectiveness of NSA partnerships is still awaiting proof. The current system produces only informal experiments and lacks systematic learning or analysis. ${ }^{59}$ While partnerships hold the potential for significant GHG reduction, ${ }^{60}$ there is, so far, no assessment of the impact of transnational climate governance, and without improved accountability arrangements it will be difficult to attest to the effectiveness of NSA-led initiatives in global climate governance. However, even when partnerships yield results, the steering hand of public power will be essential to set goals and coordinate efforts on how to achieve them.

\section{EMBEDDING PARTNERSHIPS IN MULTILATERAL CLIMATE GOVERNANCE}

While there is an ever-growing expectation that the private sector will come up with the sort of ambition that governments are lacking, there is little regulatory space in the PA for non-state action to gain traction. ${ }^{61}$ Cooperative, transnational, and polycentric governance models create new normative realities in a context where private actors have gained enormous influence but are less tightly regulated than in the national context. It is therefore time to strengthen the legitimacy as well as the effectiveness of transnational climate governance through the formulation of ground rules for partnership engagement in the context of the UNFCCC.

55 Abbott (2017), n. 10 above, p. 2.

56 D.H. Cole, 'Advantages of a Polycentric Approach to Climate Change Policy' (2015) 5(2) Nature Climate Change, pp. 114-8, at 117; Ostrom, n. 12 above.

57 T. Hickmann, 'The Reconfiguration of Authority in Global Climate Governance' (2017) 19(3) International Studies Review, pp. 430-51.

58 Ostrom (2010), n. 12 above, p. 36.

59 Abbott (2017), n. 10 above, p. 21.

60 S. Lui et al., 'Correcting Course: The Emission Reduction Potential of International Cooperative Initiatives (2020) 21(2) Climate Policy, pp. 1-19.

61 C. Streck, M. von Unger \& N. Krämer, 'From Paris to Katowice: CoP-24 Tackles the Paris Rulebook' (2019) 16(2) Journal for European Environmental \& Planning Law, pp. 165-90, at 187. 
Effective governance combines localized solutions and bottom-up engagement with regulation and (gentle) top-down management. Strategies to address global problems, such as climate change in particular, require active government steering in the context of strong institutions in addition to local and decentralized solutions. ${ }^{62}$ Orchestration is one of the proposed strategies that assigns an active management position to public agencies in the context of transnational governance. ${ }^{63}$ It exerts authority through soft modes of governance (motivating, incentivizing) ${ }^{64}$ and steers decentralized intermediaries towards activities that achieve public policy targets. The bottom-up nature of the PA, which relies on pledges to meet high-level targets, invites the active guiding and strengthening of transnational partnerships as a means to increase effectiveness, improve coordination, and increase the legitimacy of initiatives. ${ }^{65}$

The UNFCCC Secretariat is already an active orchestrator of transnational climate governance. ${ }^{66}$ Together with the high-level climate champions, the Secretariat actively promotes orchestration through the MPGCA and the LPAA, and more opportunistically through NAZCA. ${ }^{67}$ In recent years authors have proposed additional measures to strengthen existing efforts. Regime entrepreneurs - for example, the high-level climate champions - could receive active support to identify and fill governance gaps and increase the level of inter-institutional cooperation. ${ }^{68}$ The normative dimension of orchestration - in particular accountability, transparency and participation - could be reinforced by linking partnerships to clear objectives and targets. ${ }^{69}$ Another option would be the use of 'name and shame' strategies to publicize actors and initiatives that perform well and call out those that perform poorly.

Commentators also have started calling for a minimum of oversight over transnational climate partnerships, at least to the extent that they seek association and recognition under the PA. ${ }^{70}$ This includes minimum criteria for partnerships that apply for registration under NAZCA. Some criteria may be relatively easy to verify (clear

62 See also the proposal of Jane Mansbridge on the role of governments in polycentric government arrangements: Mansbridge, n. 41 above.

63 E.g., Abbott \& Snidal, n. 10 above; Hale \& Roger, n. 10 above; Abbott \& Hale, n. 10 above; Bäckstrand \& Kuyper, n. 10 above; Abbott (2017), n. 10 above; Widerberg \& Pattberg, n. 48 above; Chan \& Amling, n. 10 above; Chan \& Pauw, n. 10 above.

64 Bäckstrand \& Kuyper, n. 10 above, p. 784.

65 Abbott (2017), n. 10 above.

66 T. Hickmann \& J.P. Elsässer, 'New Alliances in Global Environmental Governance: How Intergovernmental Treaty Secretariats Interact with Non-State Actors to Address Transboundary Environmental Problems' (2020) 20(3) International Environmental Agreements: Politics, Law and Economics, pp. 459-81, at 464-6. It has also been proposed that orchestration can be done by partnerships themselves: Chan \& Pauw, n. 10 above, p. 6.

67 Bäckstrand \& Kuyper, n. 10 above, pp. 784-5.

68 Abbott, n. 6 above, pp. 80-7.

69 Bäckstrand \& Kuyper, n. 10 above (systematically reviewing the democratic values of existing orchestration attempts by the UNFCCC).

70 Widerberg \& Pattberg, n. 48 above; Pattberg \& Widerberg, n. 6 above; Chan \& Pauw, n. 10 above; O. Widerberg \& P. Pattberg, 'International Cooperative Initiatives in Global Climate Governance: Raising the Ambition Level or Delegitimizing the UNFCCC?' (2015) 6(1) Global Policy, pp. 45-56; S. Chan, C. Brandi \& S. Bauer, 'Aligning Transnational Climate Action with International Climate Governance: The Road from Paris' (2016) 25(2) Review of European, Comparative \& International Environmental Law, pp. 238-47. 
objectives and targets, transparency); others could be broader and potentially more controversial (inclusiveness, regionally balanced, ambitious, capable and able to deliver, or a track record in implementation). Eligibility criteria could be combined with monitoring and reporting obligations. Chan and Pauw (2014) and Chan and co-authors (2015) have integrated these demands in a 'Global Framework for (non-state and subnational) Climate Action', ${ }^{71}$ which would act as a long-term and politically independent framework that links NSA initiatives with multilateral processes. The framework would record existing initiatives and mobilize new action, facilitate information exchange and networking, ensure the quality of data, and monitor and verify NSA initiatives. ${ }^{72}$ Based on this, Hale and co-authors (2020) have proposed a complementary framework to assess progress, implementation, and the impact of NSA climate action. ${ }^{73}$

\section{A COMPREHENSIVE FRAMEWORK FOR PARTNERSHIP ENGAGEMENT}

The PA is open and sufficiently flexible to embrace all kinds of mitigation and adaptation contribution independent of timetables and negotiation rounds. The inclusiveness of the system makes it easier to call on NSAs to contribute their share of 'determined contributions' and ambition. While, under the Kyoto Protocol, private initiatives were often viewed with suspicion as a means to shift the responsibilities to private actors, such initiatives now more positively support the ratcheting up of national commitments in successive rounds of NDC reviews.

If private initiative were to receive full normative recognition, then deficits in legitimacy, transparency, and participation could be addressed while maximizing the potential of transnational partnerships for delivering on climate action. A combination of oversight and active support push-and-pull would anchor private initiative more formally into intergovernmental climate governance. By formulating quality and performance requirements, ensuring periodic reporting and review, and facilitating links with climate finance and government efforts, parties to the UNFCCC would ensure the integration of NSA action into the compliance framework of the PA. Partnerships would not only broadly align with the commitments, norms, and principles of intergovernmental climate action but could become part of coordinated, transformational solutions that cover whole sectors or nations.

\subsection{Creating New Spaces of Engagement and Active Orchestration}

Building on the Global Framework for (non-state and subnational) Climate Action, the proposed active orchestration would screen partnerships proposed to NAZCA against defined eligibility criteria. It would also help to monitor compliance during the

71 Chan \& Pauw, n. 10 above; S. Chan et al., 'Reinvigorating International Climate Policy: A Comprehensive Framework for Effective Nonstate Action' (2015) 6(4) Global Policy, pp. 466-73.

72 Chan et al., ibid.; Chan \& Pauw, n. 10 above, p. 36.

73 T.N. Hale et al., 'Sub- and Non-State Climate Action: A Framework to Assess Progress, Implementation and Impact' (2020) 21(1) Climate Policy, pp. 1-15. 
implementation phase and sanction underperforming partnerships with de-listing. Enhanced NSA engagement would also include the creation of an arena that actively facilitates partnership development between governments and private actors in priority areas. Through the prioritization of implementation solutions and the linking of partnerships to the formal negotiation process, partnerships could build political capital and gain financial support.

The emphasis should be on 'implementation partnerships ${ }^{, 74}$ within a solutions-oriented orchestration framework. Such partnerships can help to overcome the intention-action gap in climate politics and create evidence for collectively implemented mitigation and adaptation solutions. Breaking down larger problems into smaller, clearly defined subproblems can be a first step towards effective cooperation, not only among governments but also between governments and NSAs. The problem of tropical deforestation, for example, could be addressed through a combination of partnerships that address drivers within a particular region (for example, beef and soy production in Brazil, or cocoa production in West Africa) through a mix of finance, private commitments and national governance reform, while complementary partnerships could address the demand side of deforestation (for example, by creating an EU-China compact on sustainable soy or palm oil, or paying price premiums for sustainable cocoa). This would involve government action, donor coordination and climate finance, private commitments and investment, and implementation support by civil society. The proposed orchestration framework would help to integrate local-level interests into centrally dominated policy processes, ${ }^{75}$ address the inability of the current proliferating partnership landscape to respond to geographic imbalances, and overcome implementation barriers in developing countries by actively brokering finance and technological support.

Active orchestration capitalizes on the tendency of transnational and multi-sectoral initiatives to respond to policy signals when they steer partners - including governments - towards achieving public policy goods. It also builds on the increased efforts of the UNFCCC and state parties to facilitate partnerships and broker initiatives in the context of global climate action. The MPGCA has already led to a more effective dissemination of information and the increased involvement of developing countries. ${ }^{76}$ By further formalizing these efforts, using the system's convening power and coordination abilities, the multilateral climate regime can play an important role in engaging NSAs in collaborative forms of climate governance. It can build spaces for engagement and build coalitions of the willing, able and affected, which address defined climate implementation challenges. A link between private action, climate finance and GHG accounting methods can create incentives within a normative framework for engagement.

\footnotetext{
74 Streck, n. 17 above; C. Streck, 'The Mirage of Madrid: Elusive Ambition on the Horizon' (2020) 20(2) Climate Policy, pp. 143-8, at 146.

75 Di Gregorio et al., n. 6 above, p. 73.

76 Chan \& Amling, n. 10 above, p. 442.
} 
Table 1 Summary of the Proposed NSA Engagement and Orchestration Framework

\begin{tabular}{lll}
\hline Action & Role of the Orchestrator $\quad$ COP/CMA Decisions Party Activities Partnerships Action
\end{tabular}

\section{ESTABLISHMENT OF ORCHESTRATION FRAMEWORK}

Develop and adopt system Develop procedures for active

of active orchestration orchestration; assign staff time

and resources

\section{SCREEN AND MONITOR PARTNERSHIPS}

Ensure that partnerships meet Check compliance

minimum requirements

Monitor impact of partnerships

Collect and publish periodic monitoring reports

\section{LINK PARTNERSHIPS TO NDC AND CLIMATE FINANCE}

Increase effectiveness of

partnerships and maximize

synergies with policy priorities
Prioritize areas of mitigation and adaptation based on science and equity considerations
Mandate the UNFCC Secretariat (or other entities, e.g. the Green Climate Fund) to act as active orchestrator and define rules of engagement engagement

Integrate NSA action into the enhanced transparency framework; require submission of periodic reports from partnerships and listed NSA initiatives
Formulate criteria for partnership

Effectiveness, accountability, transparency, participation

Formulate clear objectives and measurable targets

Establish transparent

partnership governance with defined roles and decision making

Monitor and report against measurable targets using

harmonized formats

Accountability, transparency

Formulate areas for priority engagement to close urgent implementation gaps
Effectiveness, participation, inclusiveness
Accountability, transparency 
Table 1 Summary of the Proposed NSA Engagement and Orchestration Framework

\begin{tabular}{|c|c|c|c|c|}
\hline Action & Role of the Orchestrator & COP/CMA Decisions Party Activities & Partnerships Action & $\begin{array}{l}\text { Promoted System } \\
\text { Values }\end{array}$ \\
\hline $\begin{array}{l}\text { Create a platform for } \\
\text { engagement and broker } \\
\text { cooperation }\end{array}$ & $\begin{array}{l}\text { Identify main actors around a } \\
\text { particular prioritized } \\
\text { implementation challenge } \\
\text { and facilitate engagement }\end{array}$ & $\begin{array}{l}\text { Create space in the context of } \\
\text { UNFCCC meetings to allow for the } \\
\text { development of complementary } \\
\text { action and support for partnerships } \\
\text { in prioritized areas }\end{array}$ & $\begin{array}{l}\text { Participate in NSA/government } \\
\text { solutions groups for } \\
\text { collaborative implementation } \\
\text { partnerships }\end{array}$ & $\begin{array}{l}\text { Effectiveness, } \\
\text { participation }\end{array}$ \\
\hline $\begin{array}{l}\text { Link partnerships with finance } \\
\text { and NDC accounting }\end{array}$ & $\begin{array}{l}\text { Facilitate the building of public/ } \\
\text { private implementation } \\
\text { partnerships under Art. } 6 \mathrm{PA}\end{array}$ & $\begin{array}{l}\text { Develop implementation } \\
\text { partnerships under Art. 6(2) or } \\
\text { 6(8) PA }\end{array}$ & $\begin{array}{l}\text { Develop NSA action in the } \\
\text { context of integrated } \\
\text { partnerships under Art. } 6(2) \\
\text { or } 6(8) \text { PA }\end{array}$ & $\begin{array}{l}\text { Effectiveness, } \\
\text { participation, } \\
\text { inclusiveness }\end{array}$ \\
\hline Broker climate finance & $\begin{array}{l}\text { Link climate finance to } \\
\text { implementation partnerships }\end{array}$ & $\begin{array}{l}\text { Make climate finance available and } \\
\text { create a conducive policy framework }\end{array}$ & $\begin{array}{l}\text { Co-finance and implement } \\
\text { agreed activities }\end{array}$ & Effectiveness \\
\hline \multicolumn{5}{|c|}{ MONITOR EFFECTIVENESS, ENABLE LEARNING } \\
\hline Assess impact & $\begin{array}{l}\text { Conduct analysis of impact } \\
\text { and monitoring the } \\
\text { effectiveness of NSA action }\end{array}$ & $\begin{array}{l}\text { Include NSA action into global } \\
\text { stocktake }\end{array}$ & & $\begin{array}{l}\text { Accountability, } \\
\text { transparency, } \\
\text { effectiveness }\end{array}$ \\
\hline
\end{tabular}


Table 1 summarizes the various components of the proposed engagement and orchestration framework; it lists the different activities that establish, implement, and assess the framework, and suggests roles for the various actors. The parties to the UNFCCC would authorize the orchestrator (most likely the UNFCCC Secretariat) to bring together key actors (affected parties, financiers, corporate actors, experts, and local civil society) to support one or several aligned partnerships in prioritized areas of engagement. By prioritizing sectors and regions for engagement the process can help to direct attention and action towards activities that yield high-levels of GHG reductions or removals but are difficult to implement by individual state parties alone. It can also ensure that vulnerable parties receive targeted support to increase resilience and reduce the vulnerability of populations. This would increase the effectiveness and participation of partnerships. Transparency and accountability would be promoted through defined goals and milestones backed by effective MRV frameworks and periodic evaluations.

Sectoral transnational partnerships could formally be recognized as contributing to one or several NDCs in addition to establishing a partnership-specific mitigation goal. Partnerships could also be embedded in action plans supported by subsets of parties and NSAs that are destined to contribute to the solution of a particular climate challenge, which could range from new modes of transportation, a just phase-out of coal, breakthrough technologies in aviation, or smart-grid and renewable energy solutions. The involvement of private entities would link policy planning with investments, and the engagement of civil society could help to ensure a socially just transition towards a low carbon economy. Developing and developed countries could participate by focusing on aligning implementation partnerships with national policy frameworks and supporting efforts with targeted financial support.

The partnerships would be flexible and problem-oriented, based on common interest rather than global consensus. State parties would participate only where they agree effectively to contribute to tackling a particular issue. Parties that have little stake in a particular problem could opt out, ensuring that partnerships remain unburdened by intransigence. Supported transnational partnerships would bring together relevant state and non-state actors to address a clearly defined mitigation or adaptation challenge focusing, for example, on a regional adaptation challenge, the development and dissemination of a particular technology or enhancing the sustainability of defined global supply chains. By mobilizing all relevant actors, partnerships stand a better chance of overcoming financial, regulatory and governance barriers than would private or public actors on their own. In contrast to proposed climate clubs and minilateral solutions, ${ }^{77}$ they would remain anchored in the framework of the UNFCCC and the PA, and harness the complementarity of state and non-state actors.

77 In contrast, climate clubs focus on cooperation among small groups of countries. They have been proposed as 'minilateral' forums to allow effective bargaining among key countries, create incentives to encourage mitigation efforts, and combine club benefits with sanctions: W. Nordhaus, 'Climate Clubs: Overcoming Free-riding in International Climate Policy' (2015) 105(4) American Economic Review, pp. 1339-70; R. Falkner, 'A Minilateral Solution for Global Climate Change? On Bargaining 
The CMA would have to authorize the UNFCCC Secretariat to act as active orchestrator of partnerships, including in the context of Article 6 PA. Based on the proposed prioritization of action, the facilitation of such partnerships could become an active and new format during COP sessions and allow direct and responsive interactions between NSAs and state parties, which would transcend the public and private spheres of climate meetings. As part of its orchestration role, the UNFCCC Secretariat could set up an information hub to provide information on mitigation and adaptation pathways (based on reports of the Intergovernmental Panel on Climate Change (IPCC)) and prioritize areas for collaborative engagement along these pathways. An aggregated platform could allow for the identification of implementation gaps where additional partnerships are needed. Orchestration of partnerships could thus help to redress imbalances among countries by actively identifying areas of highest mitigation potential and adaptation needs, and ensuring that the concerns of weaker developing countries are represented. Backed by concrete guidelines, the UNFCCC Secretariat could ensure that there is an open 'corridor' between official negotiations and NSAs, which could facilitate the forging of concrete partnerships and agreements. ${ }^{78}$

\subsection{Collaborative NSA Partnerships under Article 6 of the Paris Agreement}

Article 6 PA is well placed to provide context and supply a framework for collaborative action, including multi-sectoral NSA partnerships. The PA encourages state parties voluntarily to cooperate in the implementation of their nationally determined contributions to allow for higher mitigation and adaptation actions and to promote sustainable development and environmental integrity' (Article 6(1)). Article 6(4) explicitly mentions private and public entities as agents to support mitigation projects; however, there is no reason why parties should not be able to authorize NSA participation under the other two modalities of cooperation, Articles 6(2) and 6(8). ${ }^{79}$ As the provisions of Article 6 remain vague and barely sketch a basic architecture for collaboration, since 2016 the COP, serving as a meeting of the parties to the PA (CMA), has sought to adopt modalities and procedures that guide the implementation of cooperative approaches - so far, without success. ${ }^{80}$

However, even without detailed guidance, the inherent flexibility of Article 6 PA allows the piloting of different forms of cooperation. Rather than putting the emphasis on a particular set of trading mechanisms, Article 6 PA promotes cooperation in any

Efficiency, Club Benefits, and International Legitimacy' (2016) 14(1) Perspectives on Politics, pp. 87101.

78 Streck, n. 17 above.

79 These provisions include flexible cooperative approaches that involve the transfer of 'mitigation outcomes' (Art. 6(2)), a mechanism that facilitates the participation of public and private entities in the projects that mitigate GHG emissions (Art. 6(4)), and a mechanism that encourages integrated, holistic and balanced non-market approaches (Art. 6(8)).

80 For updates on progress in negotiating the Paris rulebook, see Streck, von Unger \& Krämer, n. 61 above; C. Streck, M. von Unger \& S. Greiner, 'CoP 25: Losing Sight of (Raising) Ambition' (2020) 17(2) Journal for European Environmental \& Planning Law, pp. 136-60. 
form. It can provide the basis for a wide variety of transactions, ranging from resultsbased payments for reducing deforestation, to agreements that enable transactions and financial transfers among private entities, to carbon market transactions or climate finance grants that do not require any formal consideration in return for the payment. Satisfying market supporters as well as opponents, the formulations of Article 6 break with the rigid definition of the Kyoto Protocol market mechanisms and make way for cooperation that can - but does not have to - include the transfer of carbon units, and directly or indirectly involve the private sector. ${ }^{81}$

Transnational partnerships that involve two or more parties can help to increase the ambition of states' NDCs through an intergovernmental agreement defining a 'collaborative approach' under Article 6(2) PA. Such partnerships can include the transfer of carbon units, internationally transferred mitigation outcomes (ITMOs), in the parlance of Article 6(2) PA. Such ITMOs can be generated by private action through a crediting mechanism nested within government-to-government cooperation. Such governmentprivate cooperation could use the transfer of ITMOs as an incentive to measure, report, and account for the GHG emissions reductions (and removals) and establish a link to finance. However, the proposed implementation partnerships establish more involved obligations than a mere exchange of funds against emissions reductions. It would embed the transfer of ITMOs into a sectoral programme that creates incentives for private as well as public action. In the absence of an agreement on the transfer of ITMOs under Article 6(2) PA, private action could still be credited under Article 6(4) PA, a mechanism that allows the adoption of emissions reductions at the project or programme level outside an intergovernmental programme. Where no transfer of units is contemplated, the proposed partnerships could fall under non-market approaches (Article 6(8) PA) linking financial support to activities without measuring outcomes in GHG emissions reductions. In any of the described cases, all partners, including participating NSAs, would be responsible for meeting the goals of the partnership. To use a private sector concept, the success of the partnership would become part of the key performance indicators of parties and non-parties under the PA.

So far, Article 6 PA has been seen mainly as a successor to the market mechanisms of the Kyoto Protocol, and negotiations on the operationalization of these mechanisms have been cast rather narrowly within the context of carbon markets. ${ }^{82}$ This myopic view fails to do justice to the broad set of partnerships that can be forged under Article 6 - with or without market links. Various options to support transnational partnerships include:

81 C. Streck, 'Ambition Trap or Accelerator: Cooperative Approaches under the Paris Agreement' (2017) 13(2) South Carolina Journal of International Law and Business, pp. 275-301, at 296.

82 For updates on the current discussion around Art. 6 PA see W. Obergassel \& F. Asche, 'Shaping the Paris Mechanisms Part III: An Update on Submissions on Article 6 of the Paris Agreement', JIKO Policy Paper No. 5/2017, Oct. 2017, Wuppertal Institut; B. Müller \& A. Michaelowa, 'How to Operationalize Accounting under Article 6 Market Mechanisms of the Paris Agreement' (2019) 19(7) Climate Policy, pp. 812-9; L. Schneider \& S. La Hoz Theuer, 'Environmental Integrity of International Carbon Market Mechanisms under the Paris Agreement' (2019) 19(3) Climate Policy, pp. 386-400. 
- government-to-government cooperation (Article 6(2), Article 6(8) PA);

- full or partial linking of emissions trading systems (Article 6(2), Article 6(4) PA);

- agreement on offset crediting programmes between two or more partner countries, including NSAs (based on rules agreed within the partnership);

- definition of agreed rules for sectoral programmes and broader programmatic approaches in the context of multilateral partnerships (Article 6(2) or 6(8) PA);

- joint transnational implementation programmes around particular mitigation issues, such as supply chains (for example, agricultural drivers of deforestation), fuels (for example, cooperation on clean energy or shipping), technologies (such as clean modes of transportation), and similar (Article 6(2) or Article 6(8) PA, depending on whether carbon units are exchanged); and

- joint transnational implementation programmes to manage adaptation programmes across transboundary landscapes (Article 6(8) PA).

\subsection{Monitoring, Transparency, and Effectiveness}

To enable the broader UNFCCC community (NGOs, state parties, international organizations) to judge whether partnerships have achieved their goals, relevant transparency requirements of the PA would extend to listed NSA action, in general, and transnational partnerships, in particular. ${ }^{83}$ The NAZCA website could continue to recognize existing action and attract new commitments, ${ }^{84}$ but would also share information on targets, milestones, implementation progress, and the eventual climate impact of listed actions. In the case of mitigation partnerships, progress would have to be expressed in GHG emissions reduction - to the extent possible and reasonably feasible - in particular, where partnerships are integrated into broader sectoral partnerships under Article 6(2) PA or involve activities approved under Article 6(4) PA. Listed initiatives would have to submit update reports, ideally using agreed formats and applying common definitions and reporting guidelines.

Partnerships would be included in the enhanced transparency framework under Article 13 PA, though reporting requirements would have to be adjusted to apply at partnership level. Applying the principles of transparency, accuracy, completeness, comparability, and consistency (Article 4(13) PA), partnerships that receive support and are integrated into cooperative action under Article 6 PA would have to comply with corresponding MRV requirements. They would also have to provide information on implementing and achieving defined partnership goals in an analogous application of Article 13(7)(b) PA, which requires the submission of information necessary to track progress in implementing and achieving NDCs. Where partnerships benefit from support, reporting requirements would be mandatory, while other partnerships would be encouraged to submit information, following the same non-punitive and facilitative

83 C. Streck, 'Public and Private Responsibility and the Evolving Climate Regime', in T. Hickmann \& M. Lederer (eds), Leidenschaft und Augenmaß, Sozialwissenschaftliche Perspektiven auf Entwicklung, Verwaltung, Umwelt und Klima. Festschrift Professor Harald Fuhr (Nomos, 2020), pp. 221-34.

84 Available at: https://unfccc.int/news/re-energised-global-climate-action-portal-features-country-pages. 
approach that applies to action by parties. This would avoid legal or political tensions between state and non-state action regarding the proper role of various actors in addressing global problems. ${ }^{85}$

Partnerships would also be subject to review in the context of the global stocktake under Article $14 \mathrm{PA}$. The stocktake is a periodic review of the implementation of the PA, set to be conducted every five years. It takes stock of parties' climate change actions and assesses whether sufficient progress is being made towards the achievement of the long-term goals of the PA (Article 14(1) PA). During the global stocktake, progress towards mitigation, adaptation, and means of implementation and support will be conducted in the light of equity and the best available science. It will draw on individual country reports on progress made towards NDCs, as well as the latest report of the IPCC. Under current implementation guidance, the stocktake only reviews country action with the aim of adopting a collective perspective, without reviewing whether actions of any individual country are adequate. While the CMA decision at COP 24 in Katowice (Poland) provides a basis for the first stocktake in 2023, the provisions allow for flexibility. ${ }^{86}$ Therefore, reporting requirements could be extended to transnational partnerships and NSA initiatives through a simple CMA decision.

\section{ORCHESTRATION CHALLENGES}

The enhanced partnership governance proposed here addresses the risk that partnerships may discourage or replace public action and thereby trade long-term societal and transformational goals in favour of the profit expectation of private partners. Effective orchestration would link partnerships to public processes and institutions. Public orchestrators, such as the UNFCCC Secretariat, can steer private partnerships towards common goals and democratic values. This includes prioritizing implementation efforts over initiatives that promote mere networking or coordination.

However, a formalized and rule-based integration of NSA-led initiatives and partnerships into the compliance framework of the PA creates a number of additional risks. Most importantly, partnerships must maintain their bottom-up energy and should neither become dependent on nor hindered by UN bureaucracy. Partnerships would still need to be free to define their participants, objectives and targets, and governance and decision-making frameworks. As long as they meet the stipulated minimum criteria, they would be registered. The more involved facilitated implementation partnerships would come as an additional offer, not as a condition of participation. Implementation partnerships could be facilitated by the UNFCCC Secretariat, but decision making on funding and implementation schedules would remain with the partners to avoid falling victim to the institutional rigidities of UN processes.

85 Streck, n. 83 above.

86 UNFCCC, Decision 19/CMA.1, 'Matters relating to Article 14 of the Paris Agreement and Paragraphs 99-101 of Decision 1/CP.21' (2 Dec. 2018), UN Doc. FCCC/PA/CMA/2018/3/Add.2, available at: https://unfccc.int/sites/default/files/resource/CMA2018_03a02E.pdf. 
Monitoring and accounting for GHG impacts needs to remain an enabler of finance and action, not a barrier. The implementation of climate solutions must take priority over challenges in relation to GHG accounting. Where controversies exist and accounting challenges cannot be overcome, milestones can relate to implementation progress. In such cases, partnerships cannot benefit from transactions under Articles 6(2) and 6(4) PA but can still successfully be implemented.

An associated risk is that the formalization of NSA and partnership engagement in the context of the UNFCCC and the PA can easily become politicized. To avoid NSA-led initiatives and partnerships becoming political tools for state parties, the process of formalization and recognition must be managed by technical staff and guided by approved prioritization criteria. Once an area of engagement is prioritized - transformational change in a high-emitting sector, or adaptation measures in particularly vulnerable regions - the UNFCCC Secretariat as orchestrator would ensure its coverage and inclusion in the formal UNFCCC meeting agenda. It would also organize interested partners and encourage the building of implementation arrangements. However, all operational decisions would remain with the partners.

While the institutionalization of partnerships would integrate NSAs into the compliance system of the UNFCCC, they would still have a significantly different status from that of the state parties. Private action would be accounted for under the umbrella of NDCs, which remain the cornerstone of the PA. Public efforts remain essential in the long term to mandate and guide private efforts. Yet, integrating NSAs into the system of climate governance opens the door to transnational, public-private responsibility for achieving the Paris climate goals. ${ }^{87}$

\section{CONCLUDING REMARKS}

Thirty years of intergovernmental efforts to construct a legally binding, ambitious, and effective climate agreement have successively produced the meagre outcome of a framework convention with little regulatory power, an unpopular agreement that formulated obligations for few, and an agreement that puts all its trust into voluntary action, relying on peer pressure to produce a ratcheting up of ambition. It is time to involve non-state public actors (cities, regions) and private actors (corporations, NGOs) in local, national, regional, and international efforts to energize the agreement and effectively address climate change. While this requires carving out new conceptual space in the rules of the UNFCCC, this challenge seems to be surmountable. This type of regulatory engagement could be pursued with a light touch at the beginning and - together with the NDCs - grow as trust and evidence of success build.

The proliferation of transnational partnerships helps to fill implementation and ambition gaps in public action. However, current partnerships and NSA incentives suffer from governance weaknesses, such as insufficient follow-up and MRV, a bias towards powerful actors, and limited transparency. To ensure that transnational

87 Streck, n. 83 above. 
partnerships and NSA-led initiatives can effectively contribute to the PA, this article makes the case for a formalized participation and orchestration framework for NSAs.

The proposed formalized partnership engagement would rest on the pillars of (i) information collection and analysis to develop and prioritize areas of transnational and partnership engagement; (ii) defining minimum criteria and procedural requirements to be listed on an enhanced NAZCA platform; (iii) active support for strategic and essential initiatives; (iv) the facilitation of market or non-market finance, including as part of Article $6 \mathrm{PA}$; and $(\mathrm{v})$ the monitoring and evaluation of effectiveness in the context of the enhanced transparency framework (Article 13 PA) and the global stocktake (Article 14 PA). Sectoral implementation partnerships that address concrete climate policy challenges by bringing together local and national governments, technology providers, financiers and affected people could be recorded as direct contributions to NDCs. Their results would be monitored and verified.

Partnerships thereby would become a formal part of the governance architecture of the PA. The resulting multipolarity of actors and initiatives strengthens climate governance as it hedges against the risk of waning political will and the temptation of states to violate their promises in order to manage economic, political or - with particular salience - health crises. The involvement of NSAs - NGOs in particular, but also corporations and subnational public entities - increases the chance of continued climate action where national governments fail to deliver.

Establishing a formal normative link between transnational and intergovernmental climate governance could be accomplished through a number of amendments to the decision that elaborates on the transparency framework and the global stocktake, as well as broad recognition of partnerships under Article 6. The incremental effort in negotiations is very limited and is a price worth paying considering the dividends that such investment in diplomacy can carry. Constructing effective implementation partnerships, recording their mitigation and adaptation goals, and holding them accountable, may finally move climate rhetoric to climate action. 